$\mathbb{T}$ periodica polytechnica

Mechanical Engineering

$53 / 2$ (2009) 6168

doi: 10.3311/pp.me.2009-2.02

web: http://www.pp.bme.hu/me

(c) Periodica Polytechnica 2009

RESEARCH ARTICLE

\section{Power flows and efficiency analysis of out- and input coupled IVT}

\author{
Zsolt Farkas / György Kerényi
}

Received 2010-01-18

\begin{abstract}
Since late 1995, when the high-powered (194 kW) Fendt Favorit 926 equipped with a "Vario" transmission was launched, power machines with CVT (Continuously Variable Transmission) have appeared on the palette of all major tractor manufacturing companies as well. The CVT unit in the transmission of these power machines is not included directly in the power flow, but in one of the power branches after a split. By modifying the gear ratio of a properly selected CVT unit, the transmission can be geared neutral and the direction of progress of the vehicle can be changed. The transmission structure produced so is called power split IVT (Infinitely Variable Transmission).
\end{abstract}

The paper presents the ways of producing an IVT drive and analyzes the Fendt "Vario" driving mechanism with OC-RSC structure and the same elements but with IC-RSC structure. There is detailed analysis on both structures on power flows (power split, positive/negative power circulating), the Geared Neutral and the backward operational stages, taking into account the significant states from efficiency calculation point of view, together with changes thereof in function of output revolution. Based on these investigations it is highlighted that the entire range of the course of the vehicle can be covered by an output coupled system adjusting the gear of the CVT unit within the high-efficiency range. The task is the same for input coupled systems, to be realized by planetary gears installed after the IVT unit and by the proper control of their engagement.

\section{Keywords}

CVT $\cdot$ IVT $\cdot$ power split $\cdot$ efficiency $\cdot$ power flow $\cdot$ tractor

\section{Acknowledgement}

The authors wish to acknowledge the technical assistance of the Hungarian Institute of Agricultural Engineering. Furthermore thanks for the support of Hungarian Scientific Research Found (OTKA K62875).

\section{Zsolt Farkas}

\section{György Kerényi}

Department of Machine and Product Design, BME, H-1111 Budapest, Múegyetem rkp.3, Hungary

\section{Introduction}

Leonardo DaVinci sketched the first CVT (Continuously Variable Transmission) in 1490 [1]. Long time has passed since the first records and continuously variable transmission technology has been applied in more and more areas. The CVT mechanisms developed for agricultural power machines had no success until the 1960s and 1970s because of their low efficiency. In the 1980s and 1990s, hydrostatic-mechanical power split transmission mechanisms - stepless by speed ranges - were of higher efficiency, but they were only produced at prototype level (e.g.: Hungarian VARI-TRAK 4x4, Jarchow transmission, Kirste Renius: LTM Forschungs-Tractor, etc.). A real breakthrough was brought about by the serial production of $194 \mathrm{~kW}$ Fendt Favorit 926 with "Vario" transmission, presented in late 1995 [2]. And in the course of the past fourteen years, models with continuously variable transmission appeared in the product palette of nearly all manufacturers (Table 1 .

\section{Evaluation of CVT mechanisms}

A CVT unit can be integrated into a drivetrain in two ways. One of them is mounting directly into the power flow (Fig. 11 $)$, the other is mounting into a branch created by power split (Figs. 1p and 14). The continuously variable power split transmission mechanisms thus produced can be divided into two further main groups. One of the main groups consists of single (Fig. 1p), the other of multiple power split transmission mechanisms (Fig. 1 ). There are various structural designs for CVT units [3]. Apart from one or two exceptions, the CVT unit of serially produced continuously variable tractor transmission is hydrostatic (Table 1). This transmission type ensures the most shifting options.

The transmission structure so produced is called power split IVT (Infinitely Variable Transmission). The IVT produced as above can be used for various purposes:

1 to improve total efficiency;

2 to increase the transmission ratio range.

Unfortunately, these goals cannot be reached simultaneously, as the ratio range is reduced the efficiency increases, and an in- 
Tab. 1. Commercially available CVT tractor models

\begin{tabular}{|c|c|c|c|}
\hline The Type of Tr & mission & CVT Unit & The Type of Tractor \\
\hline \multirow{6}{*}{ Fendt } & \multirow{6}{*}{$\begin{array}{l}\text { „Vario" } \\
\text { "Dyna-VT" } \\
\text { "V-tronic" } \\
\text { "TechStar" } T M "\end{array}$} & \multirow{6}{*}{$\begin{array}{l}\text { Hydrostatic } \\
\text { (primary and secondary con- } \\
\text { trols) }\end{array}$} & Fendt Vario $312,400,700,800,900$ \\
\hline & & & Massey Ferguson 7400, 8400 \\
\hline & & & \\
\hline & & & \\
\hline & & & JCB Fastrac 8250 \\
\hline & & & Challenger MT $500 \mathrm{~B}, 600 \mathrm{~B}$ \\
\hline Claas & „HM" & & Claas Xerion \\
\hline \multirow{3}{*}{ Steyr (ZF) } & \multirow{2}{*}{ „S-Matic” } & \multirow{3}{*}{ Hydrostatic (primary controls) } & Steyr CVT 120, 130, 150, 170 \\
\hline & & & Case CVX 120, 130, 150, 170 \\
\hline & AutoCommand $^{T M}$ & & $\begin{array}{l}\text { New Holland TVT 135, 145, 155, } \\
170,190\end{array}$ \\
\hline \multirow{5}{*}{$Z F$} & \multirow{5}{*}{ „Eccom” } & \multirow{5}{*}{ Hydrostatic (primary controls) } & John Deere 6420, 6620, 6820, 6920 \\
\hline & & & $\begin{array}{l}\text { Deutz Fahr Agrotron TTV 1130, } \\
1145,1160\end{array}$ \\
\hline & & & Claas Xerion 3300,5000 \\
\hline & & & McCormick VTX 170-190 \\
\hline & & & Terrion ATM 7000 \\
\hline John Deere & „AutoPowr” & Hydrostatic (primary controls) & John Deere 7010, 8030 \\
\hline New Holland & „EasyDrive” & Chain variator (PIV) & New Holland Boomer \\
\hline Carraro & „VaryT” & Toroid variator & Carraro T 15.0, T 10.0, T 5.0 \\
\hline Valtra & „Nordic” & Hydrostatic & Valtra Direct \\
\hline $\mathrm{CNH}$ & „AutoCommand" & Hydrostatic (primary controls) & New Holland T 7000 \\
\hline Belarus & - & Electromechanical & Belarus 3023 \\
\hline
\end{tabular}

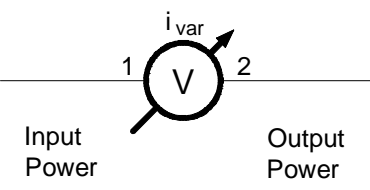

a, direct integration

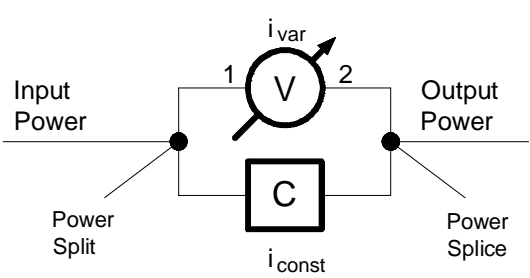

b, single power split

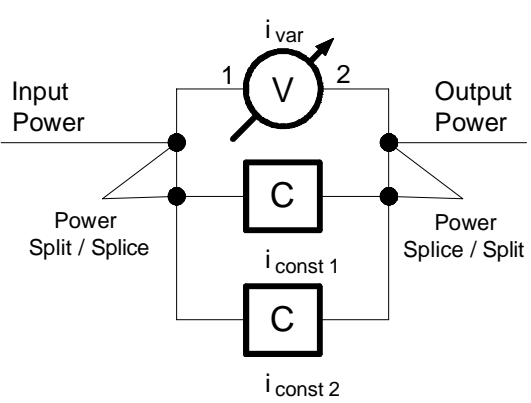

c, multiple power split

Fig. 1. Options for mounting a CVT unit into the drivetrain (schematic diagrams)

creased ratio range results in the reduction of total transmission efficiency.

Four basic structural components are required for producing the simplest IVT structures (Fig. 2), namely: coupling member of constant speed, coupling member of constant torque, power branch of constant gear and power branch of infinitely variable gear. If the coupling member of constant speed is on the input side, the resulting system will be input coupled (IC) (Fig. 2a) with split torque; if it is on the output side, the resulting system will be output coupled (OC) (Fig. 2a) with split speed. Out of the models commercially available, transmission of Fendt is of the OC (Output Coupled) type, all the rest are IC (Input Coupled).

Let us assume that the coupling member of constant torque is an EI type planetary gear (E means external, I means internal toothing) [4]. The planetary gear is indicated by P in Fig. 2. The abbreviations of the three basic elements of an EI type planetary gear according to the English terminology are the following: "Sun gear" S, "Ring gear" R, "Carrier" C. In case of a stepless, constant gear, and input coupled (IC) system, there are several ways of connecting the output shaft - and in case of an output coupled (OC) system, the input shaft - to the three basic components (S, R, or C) of a EI type planetary gear of two degrees of freedom.

Thus, by combining basic structural components, twelve different structures can be created (Table 2). The number of different structures due to kinematics equivalence can be reduced to 


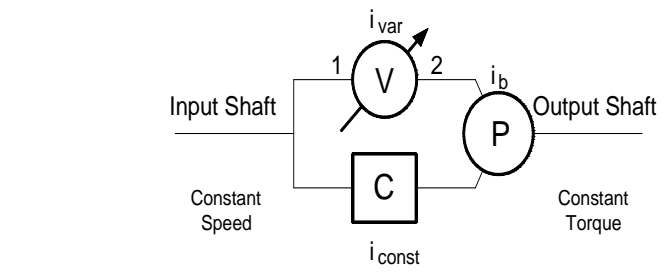

a, input coupled (IC)

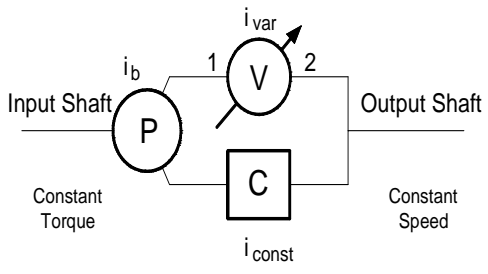

b, output coupled $(\mathrm{OC})$

Fig. 2. The two ground type of single power split infinitely variable transmissions

six. On the basis thereof, "Vario" transmission is the structure indicated by the OC-RSC code (Fig. 3a). In the signage, OC means output coupled, the first letter $(\mathrm{R})$ refers to the connection with the CVT component, the second letter (S) to that with the component of constant gear, and the third letter $(\mathrm{C})$ to that with the input shaft.

\section{Analysis and modelling of the basic components of IVT structures}

The basic components of an IVT structure were examined one by one in detail. The input and the output of the basic components were analysed in view of speed, torque and power. The gear ratio between output and input and efficiency were taken into consideration during modelling.

\subsection{Variable gear}

In high-power machines, the variable gear unit is a mechanical or hydrostatic transmission, except for the Belarus electromechanic transmission. The accurate modelling of a CVT unit is quite complicated due to parameters depending on both the speed of revolution and the torque. The most accurate results for the gear ratio between inputs and outputs and for efficiency values would be provided by the results measured on the transmission test bench. Therefore the simulation model is built up to directly integrate the field values of speed of revolution, torque, and the characteristic curve of efficiency yielded by measurements. In this study, the efficiency of the variable gear unit was taken into consideration with a constant value independent from the gear ratio and the applied torque.

\subsection{Planetary gear}

The speed of revolution correlation between the basic components of the planetary gear (S, R and C), based on the Willis basic equation, is:

$$
\left(1-i_{b}\right) \cdot n_{C}=n_{S}-i_{b} \cdot n_{R}
$$

Where $\mathrm{i}_{b}$ is the internal gear ratio of the planetary gear, which can be determined by the speeds of the basic components, applying them to a carrier by definition, and can also be expressed by the tooth numbers of basic components (2).

$$
i_{b}=\frac{n_{S}-n_{C}}{n_{R}-n_{C}}=-\frac{z_{R}}{z_{S}}
$$

The relation of torques is only determined by the internal gear ratio $\mathrm{i}_{b}$ and efficiency $\eta_{S R}$ and $\eta_{R S}$. The order of letters in the index shows the direction of power flow.

From the torque balance of the planetary gear:

$$
T_{S}+T_{R}+T_{C}=0
$$

When carrier does not rotate, from the power balance in both power flow directions:

For sun gear input:

$$
T_{R} n_{R}=-T_{S} n_{S} \eta_{S R}
$$

For ring gear input:

$$
T_{R} n_{R}=-T_{S} n_{S} / \eta_{R S}
$$

By summing up both efficiencies and introducing $\eta_{0}^{W 1}$ the torque relation independent of power flow direction will be:

$$
\frac{T_{R}}{T_{S}}=-\frac{n_{S}}{n_{R}} \cdot \eta_{0}^{w 1}=-i_{b} \cdot \eta_{0}^{w 1}
$$

It follows from (3) and (6) that:

$$
\begin{aligned}
& \frac{T_{C}}{T_{S}}=i_{b} \cdot \eta_{0}^{w 1}-1 \\
& \frac{T_{C}}{T_{R}}=\frac{1}{i_{b} \cdot \eta_{0}^{w 1}}-1
\end{aligned}
$$

Based on the signs given in the literature [5], the $w 1$ index comes from the sign of the rolling power $\mathrm{P}_{w 1}$ on the shaft of the sun gear. If $\mathrm{P}_{w 1}>0$, rolling power flows from the sun gear to the ring gear; if $\mathrm{P}_{w 1}<0$, it flows from the ring gear to the sun gear. The defnition of $\eta_{0}^{w 1}$ for calculations follows from this:

$$
\begin{aligned}
& w 1=+1 \rightarrow \eta_{0}^{w 1}=\eta_{S R} \\
& w 1=-1 \rightarrow \eta_{0}^{w 1}=\frac{1}{\eta_{R S}}
\end{aligned}
$$

Eqs. (1) to (10) above can be used for calculating the speeds of the missing basic component(s) on the basis of input parameters $\mathrm{Z}_{S}, \mathrm{Z}_{R}$ (sun-, ring gear tooth numbers) and input data; and on the basis of the tooth efficiency calculation described at the cylindrical cogwheel connection and the bearing loss of the planetary gear, torque and output values can be determined by taking the power flow direction into account. 
Tab. 2. Single power split infinitely variable transmission structures

\begin{tabular}{|c|c|c|c|c|c|c|c|c|c|c|c|c|}
\hline Structures: & SCR & $\mathrm{RCS}$ & SRC & RSC & CRS & CSR & SCR & RCS & SRC & RSC & CRS & CSR \\
\hline $\begin{array}{l}\text { Internal gear } \\
\text { ratio of the } \\
\text { planetary gear: }\end{array}$ & $\mathrm{i}_{b}$ & $1 / i_{b}$ & $\mathrm{i}_{b}$ & $1 / i_{b}$ & $\mathrm{i}_{b}$ & $1 / i_{b}$ & $\mathbf{i}_{b}$ & $1 / i_{b}$ & $\mathbf{i}_{b}$ & $1 / i_{b}$ & $\mathrm{i}_{b}$ & $1 / \mathrm{i}_{b}$ \\
\hline $\begin{array}{l}\text { Equivalent } \\
\text { structures: }\end{array}$ & & SCR & & $\mathrm{BRC}$ & & -CRS & & -SCR & & -SRC & & CRS \\
\hline
\end{tabular}

\subsection{Constant gear}

Tooth efficiency can be determined on the basis of the tooth numbers of the connecting gears $\left(\mathrm{Z}_{1}\right.$ and $\left.\mathrm{Z}_{2}\right)$, based on equation (11) were $\mu_{Z}=0,04$ is the coefficient of friction. In case of an EI type gear connection the "-“ sign, and in case of an EE type gear connection the sign " + " is required [10].

$$
\eta_{0}=1-2,1 \cdot \mu_{Z} \cdot\left(\frac{1}{Z_{1}} \pm \frac{1}{Z_{2}}\right)
$$

\subsection{Bearing}

Friction in the rolling bearing is a determining factor, its influences the operating temperature. Bearing friction depends on load and other factors, the most important of which are the bearing type and size, the operating speed, the properties and quantity of the lubricant. The total resistance to rolling in a bearing is made up of the rolling and sliding friction in the rolling contacts, the friction in the contact areas between the rolling elements and the cage as well as on the guiding surfaces for the rolling elements and the cage, the friction in the lubricant and of the sliding friction of rubbing seals in the case of sealed bearings.

The modelling of bearing loss is quite complex [6]. This study does not contain detailed modelling, only a simplified version thereof. This simplification was based on planetary gear tests performed at our department [7]. On the basis thereof, bearing losses were taken into consideration at 1 per cent of rolling output power.

\section{Testing of IVT systems}

Three different operational states can be distinguished in CVT power split transmission mechanisms based on the power flows generated [8]. One of them is power split (PS), when power flows along power branches of both the constant and the variable gear. The other is power circulation, within which there are positive and negative operational states. Positive power circulation $(+\mathrm{PC})$ means that the sum of power coming from the input shaft and of circulating power flows through the power branch of variable gear. In case of negative power circulation (-PC), aggregate power passes through the power branch of constant gear, and the CVT unit is only loaded by circulating power. These operational states must be further broken down in order to accurately analyse and calculate efficiency. Particular attention must be paid to the state of geared neutral and to the clutch state of the planetary gear [9].

\section{Analysis of OC-RSC and IC-RSC transmissions}

Using basic structural components, the Fendt "Vario transmission of OC-RSC structure" (Fig. 3a) and the IC-RSC structure, the mirror image of the former was examined (Fig. 4 ) by using the same components. The double heavy lines in the figures indicate the bearings in the tests.

Test parameters were the tooth number of sun- and ring gear $\left(Z_{S}=50, Z_{R}=110\right)$, the speed of revolution of input shaft $\left(n_{I N}=19001 / \mathrm{min}\right)$, the torque of input shaft $\left(T_{I N}=1002\right.$ $\mathrm{Nm})$ and the gear ratios $\left(i_{C 1}=-3, i_{C 2}=-1\right)($ Fig. 3a and $4 \mathrm{a})$.

Fig. 3/b shows the analysing tables of OC-RSC, and Fig. $4 \mathrm{p}$ shows that of IC-RSC. The following assumptions are made in order to specify power flows:

- Input drive means that the direction of the active force and of rolling point speed are identical.

- Power introduced into the transmission is always positive.

- Output drive means that the direction of the active force and of rolling point speed are the opposite.

- Output power is always negative.

The first column of the tables on the input and output shafts of each basic component shows the signed values of speed, the second those of torque, and the third those of power. The first row of the tables illustrates the operational state of (PS); the second that of $(-\mathrm{PC})$; the third that of $(+\mathrm{PC})$, the fourth that of Geared Neutral $\left(\mathrm{P}_{\text {Const }}=0-\mathrm{GN}\right)$; and the fifth the one when no power flows through the branch of variable gear $\left(\mathrm{P}_{V a r}=0\right)$.

The operational state of power split should be further broken down for efficiency analysis, as this operational state includes the highest efficiency state of the planetary gear, namely the clutch state. This separates power flow from the sun gear to the ring gear and from the ring gear to the sun gear. Fig. $5 \mathrm{a}$ OCRSC and 5.b IC-RSC shows the Kutzbach speed figures of these three operational states of the planetary gear.

Our tests were performed separately by taking into consideration, the tooth efficiency, the efficiency of the component of variable gear, and the friction losses of bearings. The efficiency of the component of variable gear was taken into consideration as a value $\eta_{V a r}=0.87$ regardless of the gear ratio. Fig. 6a shows power proportions in function of output revolution for the $\mathrm{OC}$ RSC structure, and Fig. 6p for the IC-RSC structure. 

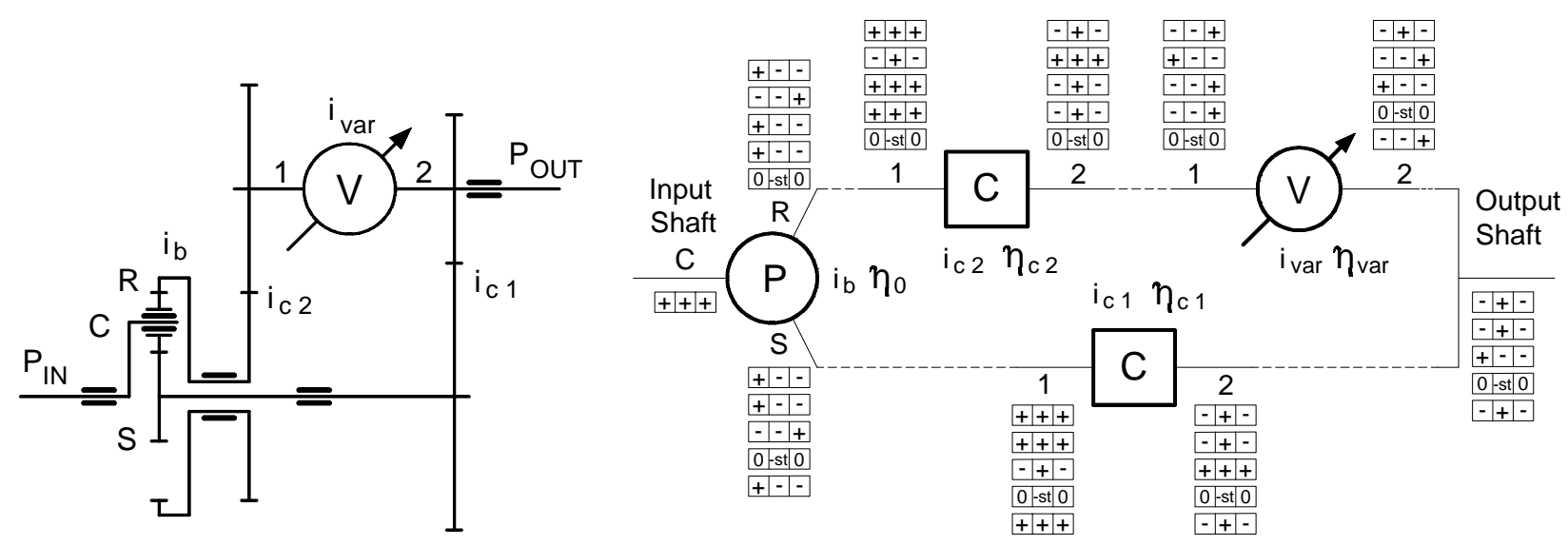

a, Transmission structure

b, Analysing tables of the operational states

Fig. 3. OC-RSC transmission
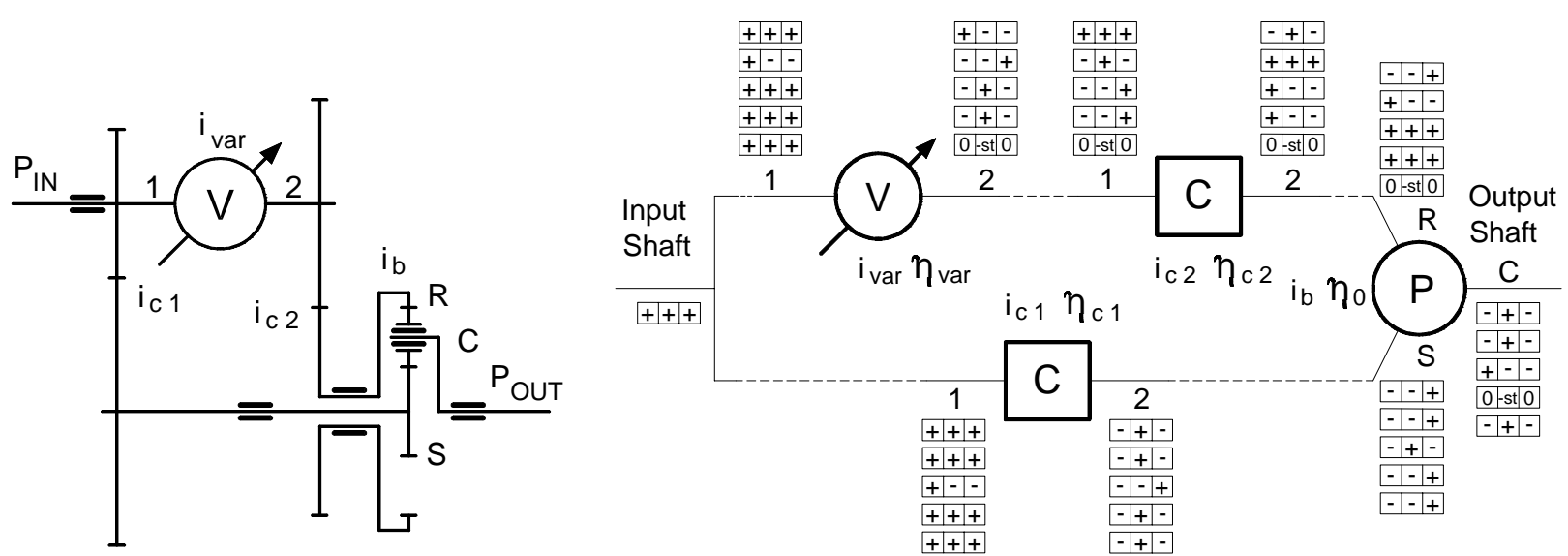

a, Transmission structure

b, Analysing tables of the operational states

Fig. 4. IC-RSC transmission

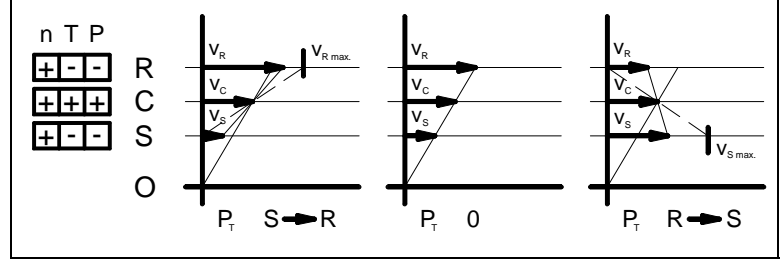

a, OC-RSC structure

Fig. 5. Kutzbach speed figures of the power split state of the planetary gear

Fig. 77 shows ratio change of gear ratio of variable gear in function of output revolution for the OC-RSC structure, and Fig.7p for the IC-RSC structure.

Fig. 8 shows efficiency changes in function of output revolution for the OC-RSC structure, and Fig. $8 \mathrm{p}$ for the IC-RSC structure. Let us note that the boundaries of changes between operational states are shifted by taking efficiency values into consideration. In addition to taking tooth and bearing loss into consideration, Figs. 6, 7 and 8 indicate the boundaries corresponding to the figure of $\eta_{V a r}=0.87$.

Fig. 9 a shows the total efficiency changes at different constant efficiency values in the variable gear unit as a function of output revolution for the OC-RSC structure, and Fig. 9 b for the IC-RSC structure.

\section{Conclusions}

According to the analysis presented above the following conclusion can be drawn. Depending on the structure and applied operational state of the system, total transmission efficiency is affected by different way:

- First: by the efficiency of the components of variable gear and by changes. 


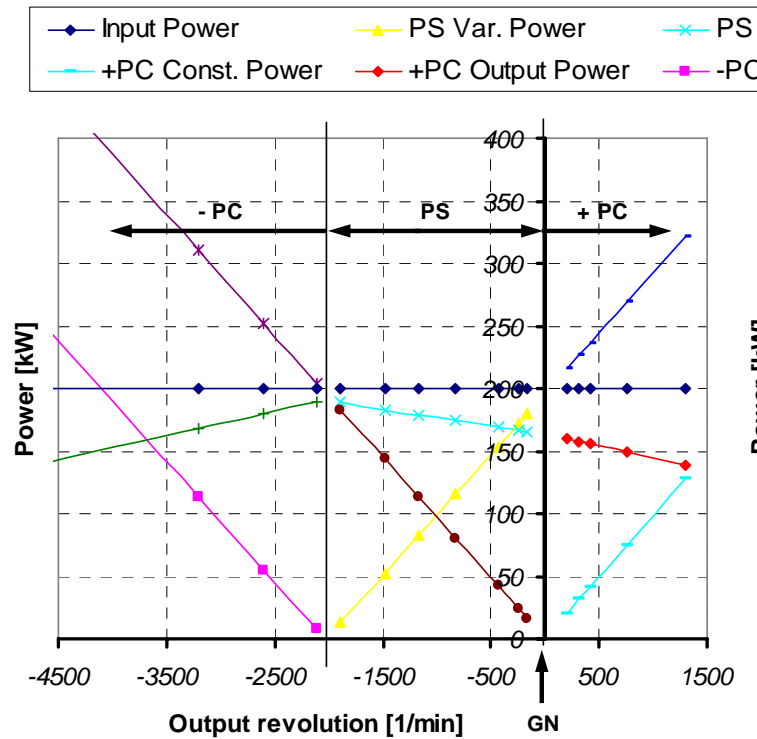

a, OC-RSC structure

S Output Power $\quad \rightarrow$ PS Const. Power -+ PC Var. Power

PC Var. Power $\quad *-$-PC Const. Power $\rightarrow$-PC Output Power

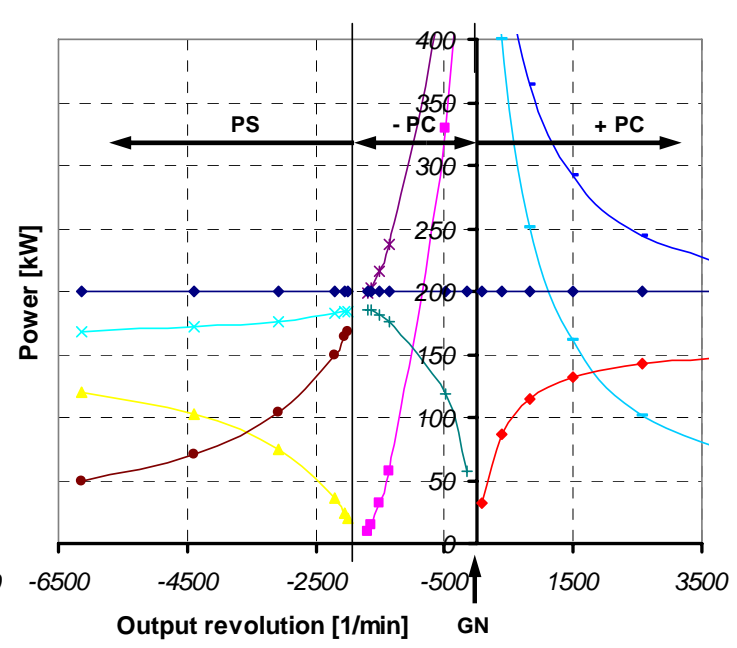

b, IC-RSC structure

Fig. 6. Power ratios of the transmissions in function of output revolution

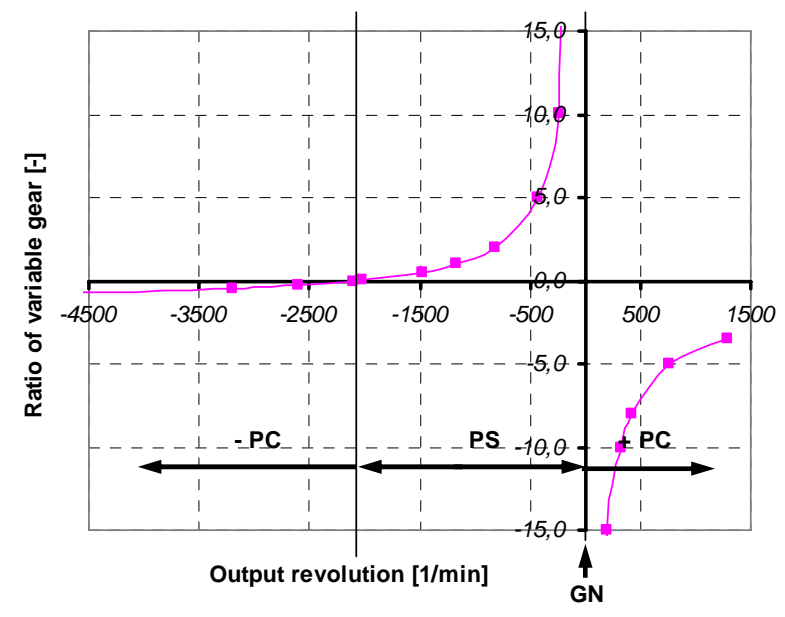

a, OC-RSC structure

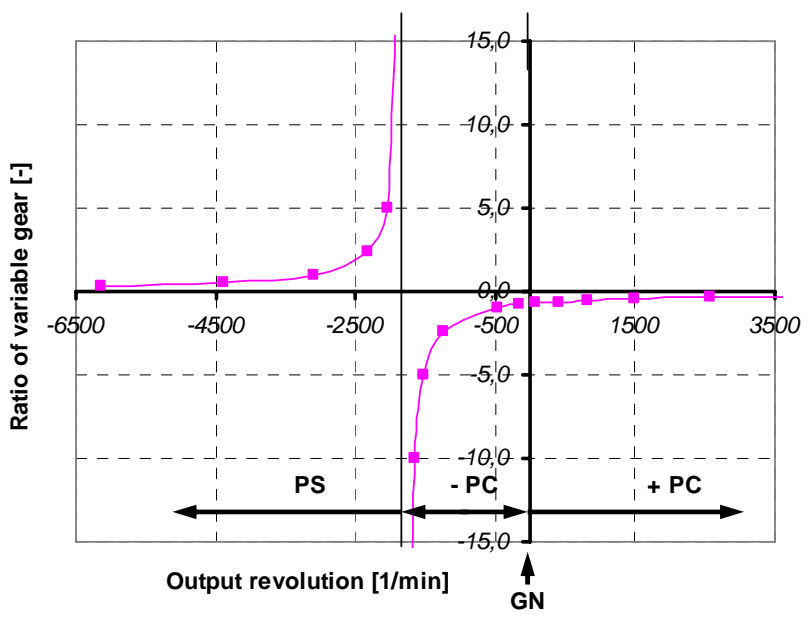

b, IC-RSC structure

Fig. 7. Ratio change of variable gear in function of output revolution $\left(\mathrm{n}_{I N}=19001 / \mathrm{min}\right)$

- Second: by the tooth friction.

- Third: by bearing friction, the values of which increase as the speed increases.

The third is loss by bearing friction, the values of which increase as the speed increases.

The finding for OC-RSC:

1 At start, power flows through the branch of variable gear ratio, therefore total transmission efficiency highly depends on the efficiency of this branch. By decreasing the gear ratio the vehicle starts and power is continuously lead through to the branch of constant gear having higher efficiency, and total efficiency is improved in the meantime. At higher speeds, efficiency will considerably decrease due to speed-dependent losses and the negative power circulation in the range of $\sim-1.36<i_{\text {Var }}<0$.

2 By changing the gear ratio $\left(i_{V a r}>0\right)$, a large gear range $\left(0<\mathrm{n}_{\text {OUT }}<\sim 20201 / \mathrm{min}\right)$ can be covered without drasti- cally changing total efficiency $\left(0.83<\eta_{\Sigma}<0.96\right)$. Therefore this transmission should only be used in this range in forward gear.

3 By further changing the gear ratio $\left(i_{V a r}<\sim-1.36\right)$, the direction of motion of the vehicle will be changed. Efficiency will be further decreased from the initial value more and more drastically $\left(<\eta_{\Sigma}<0.83\right.$ ), due to increased speed and the positive power circulation generated. Therefore this transmission should be operated for short periods and at low speeds in reverse drive. 

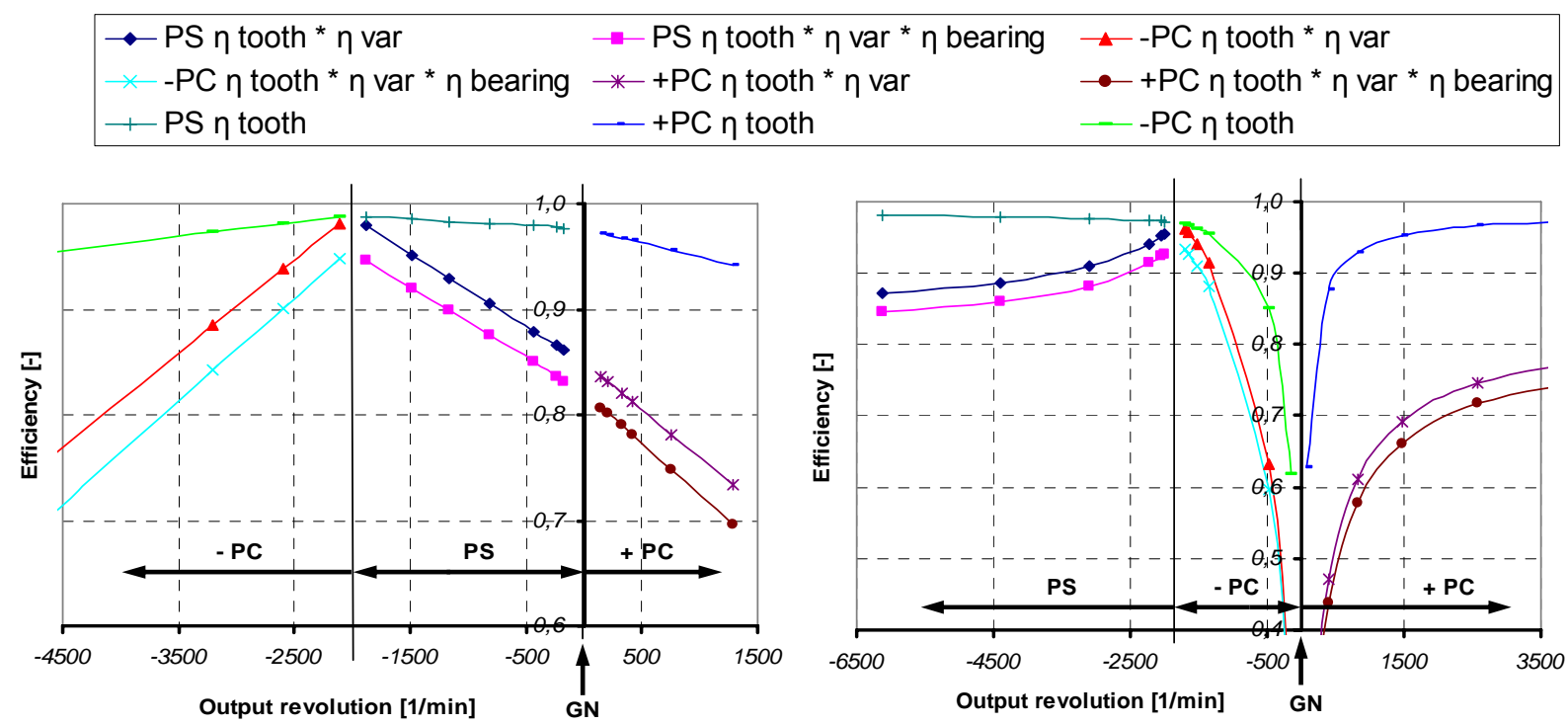

a, OC-RSC structure b, IC-RSC structure

Fig. 8. Efficiency changes of the transmissions in function of output revolution

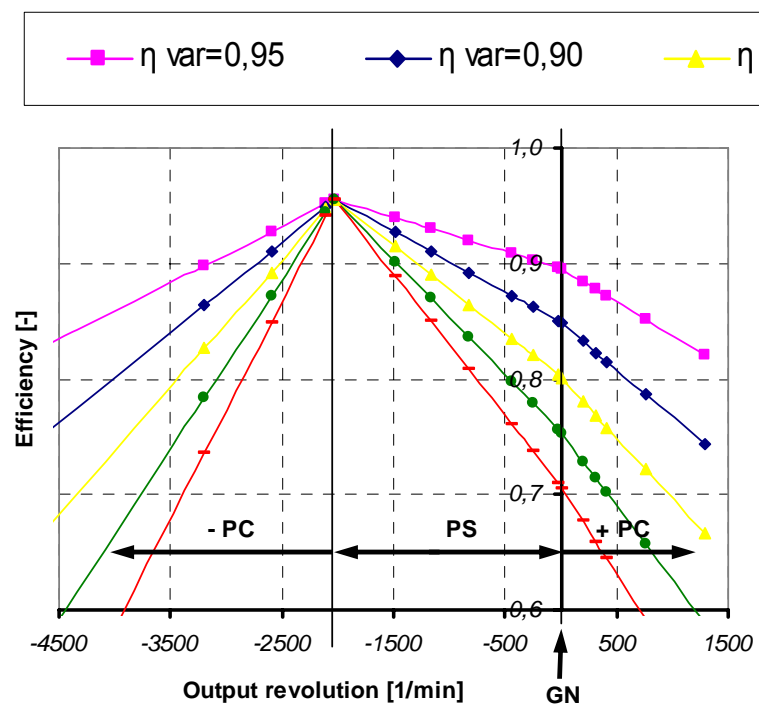

a, OC-RSC structure $\operatorname{var}=0,85 \quad \longrightarrow \eta \operatorname{var}=0,80$

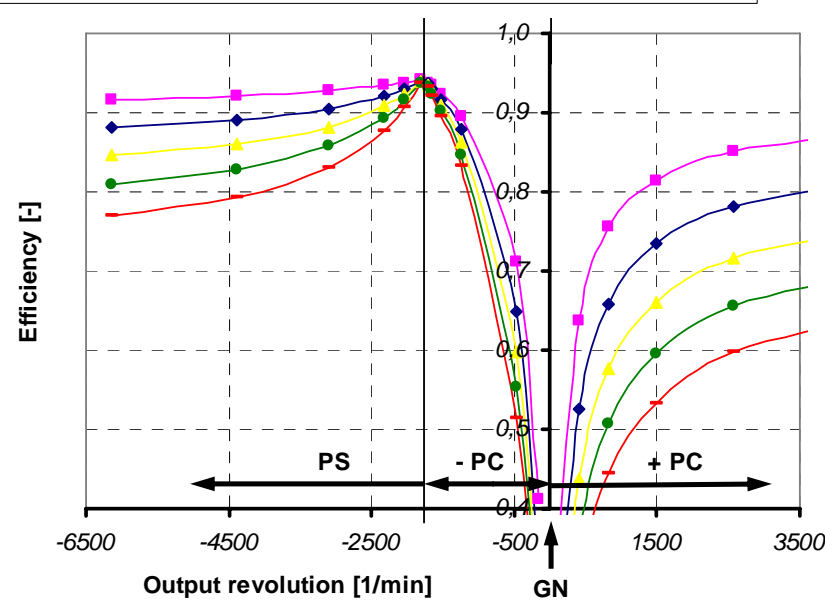

b, IC-RSC structure

Fig. 9. The total efficiency changes at different constant efficiency values in the variable gear unit as a function of output revolution 
The finding for IC-RSC:

1 At start, total transmission efficiency is very low by reason of power circulation.

2 By decreasing the gear ratio $\left(i_{\text {Var }}<-0,733\right)$, the vehicle starts and the value of power circulation will be lower and lower, therefore total efficiency will increase $\left(\eta_{\Sigma}<0,94\right)$. The best efficiency is provided in the case of $\mathrm{i}_{V a r}=\infty$, as no power will flow along the branch of variable gear ratio. By further reducing the gear ratio, total efficiency will will decrease due to the power split state and higher speed.

3 By increasing the gear ratio $\left(0>\mathrm{i}_{\text {Var }}>-0,733\right)$, the vehicle will start backward, the value of power circulation will be lower and lower, therefore total efficiency will improve.

4 Therefore this transmission can be operated at higher efficiency $0,86<\eta_{\Sigma}<0,94$ and $0,90<\eta_{\Sigma}<0,94$ only in the range of $\mathrm{i}_{\text {Var }}<-2,4$ and $\mathrm{i}_{\text {Var }}>2,4$ which covers a small speed range $\left(12371 / \mathrm{min}<\mathrm{n}_{O U T}<23261 /\right.$ min) and does not include the starting state. Therefore this transmission can only be covered by breaking down the entire speed range into several speed ranges as required, and by applying several different planetary gear ratios.

Developed models can be used for analysing and testing any kind of single power split transmission structure.

\section{References}

1 Stuart B, Audi takes CVT from 15th century to 21st century, SAE International, 2007.

2 Renius K Th, Trends in Tractor Design with Particular Reference to Europen, Journal of Agricultural Engineering Research 57 (1994).

3 Höhn B R, Stufenlos verstellbare mechanische Getriebe, VDI Berichte Mr. 618 (1986).

4 Terplán, Apró, Antal, Döbröczöni, Fogaskerék- bolygómúvek, Múszaki Könyvkiadó, Budapest, 1979.

5 Müller H W, Wirkungsgradberechnung von Planetengetriben, Antiebstechnik 34 (1995), no. 3.

6 SKF General catalogue.

7 Csobán A, Kozma M, Investigation of the Energy Losses Generated by the Oil Churning, the Bearing and the Tooth Friction in Planetary Gear Drives, 17th International Colloquium Tribology, Technische Akademie Esslingen, 2010.

8 Birkle H G, Das Betriebsverhalten der stufenlos einstellbaren Koppelgetriebe, 1968. Dissertation TH Darmstadt.

9 Farkas Zs, Analysis of single power split Infinitely Variable Transmissions, XV. International Conference in Mechanical Engineering, OGÉT, 2007.

10 Niemann G, Winter H, Maschinenelemente II., Springer, Berlin, 1989. 